\title{
Web GIS Based Spatial Data Infrastructure (SDI) System for Forestry Management in Sri Lanka
}

\author{
D.M.S.L.B. Dissanayake \\ Department of Environmental Management, Rajarata University, Sri Lanka \\ dissanayakedmslb@gmail.com
}

\begin{abstract}
Web mapping is the process of using geo-spatial information through the cyberspace. It consists both a service activities and end-user activities. Web GIS emphasises geo-data distribution aspects more involved with design aspects such as data accruing, storage, processing with server software architecture such as data storage and algorithms. Web based system is more advanced than stand-alone system because its provide pathway to overcome geographical boundaries. As a result of this one, any user who has internet facility will be able to access the system.

This paper aims to address the role of Spatial Data Infrastructure (SDI) as a framework for the development of a web-based system as a tool for facilitating forestry management by resolving current problems with spatial data. Centralise web GIS tool facilitates to visualisation and update geo-spatial data for forestry management sector in Sri Lanka. This research is a one of node to open the gate to access the cyberspace which consists of SDI.

Collected forest data were cross checked with existing GIS data sources and Google Earth before incorporate to the system. Web system was created using HTML5 and PHP language. Google Map class library and Java script library were used to render the Google Map to the web GIS system and Arc GIS cloud database is used as a geo-database for storing forestry data. in addition to that, several software packages have been used such as Adobe Dreamweaver, Adobe Photoshop, PHP editor, MySQL database, Java, Ajax, Arc GIS, Arc server etc.
\end{abstract}

Web administrator will be able to maintain and update the system using the given authentication facility and to maintain and change query function of the geo-database. End user will be able to read the map and gather information using attribute data. In addition to that, the system facilities to get the print out of the selected area with all map components such as legend, map title, scale etc.

Keywords: Web GIS, Cloud GIS, Forest management, SDI, GIS modelling 